\title{
The Invaluable Institutional History: Ghana's National Museum from a Obroni Perspective
}

\author{
BRITNEY D. GHEE
}

$\mathrm{P}$

erhaps it is the historical nature of African-American history that led me to understand the importance of transnational history. As Robin Kelley argues in a special issue of the Journal of American History that focused on the emergence of the transnational approach, African-American history, as well as Chicano/a studies and AsianAmerican studies, 'were diasporic from their inception'. They require historians to not only look internally within the United States, but at the larger Black Diasporic community. ${ }^{.}$Du Bois sought to find the source of African-American culture through an investigation of not only American society, but by examining cultural similarities within the Atlantic world. Kelly argues that the intrinsic nature of transnationalism within AfricanAmerican history is rooted in the African-American intellectual's fight 'for freedom, justice, and self-determination', unlike the academic movement in the late twentieth century which sought to 'put national

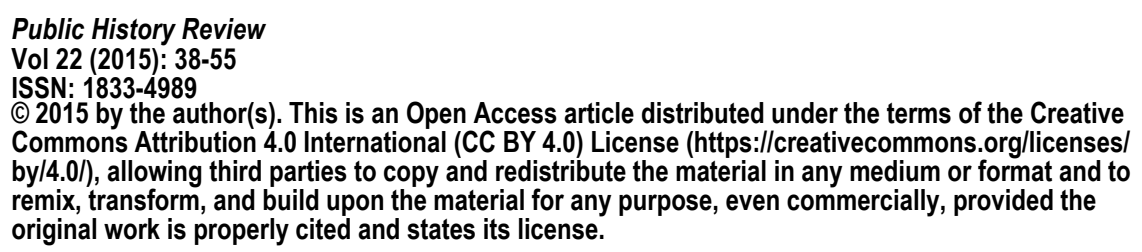


developments in context, and to explain the nation in terms of its crossnational influences'. ${ }^{2}$ Ian Tyrell investigates the purpose of the transnational approach, distinguished from comparative history, which he argues 'tended to treat national borders as a given', and ultimately concludes that it focuses 'on the relationship between nation and factors beyond the nation' ${ }^{3}$ Tyrrell and Kelley's definitions and understanding of transnational history are beautifully illustrated within the case study of the National Museum of Ghana. Conceived during colonialism, curated during an in influential independence movement and further defined by the emerging role of tourism within its national economy, the National Museum is a source of Ghanaian identity creation that is heavily influenced by its institutional history and the influx of international interpretation.

\section{GHANAIAN IDENTITY FORMATION}

Named after an ancient African kingdom actually found further inland, Ghana was the first sub-Saharan African country to gain its independence on 6 March 1957. A combination of the former British colony of the Gold Coast and the Togoland trust territory, Ghana's borders encompass more than eight major ethnic groups, 26.3 million people and fourteen national languages. ${ }^{4}$ Borders created by European colonizers defined the geographical bounds of Ghana. But the Ghanaian identity was created by the independence movement of the 1950s and the Nkrumah government. Kwame Nkrumah - the leader of the independence movement, advocate for African Unity and the country's first president - recognized that in order to create a successful, independent state out of an ethnically and culturally diverse Ghana, the formation of a national identity would be required. As Kankpeyeng and DeCorse have observed, 'Monuments served as a means of creating a uniform cultural identity', and this perfectly encapsulated the Nkrumah government's goal of creating an identity founded upon his motto of unity in diversity. ${ }^{5}$ Nkrumah encouraged total African independence, which he saw only possible through African unity based upon African Personality. African Personality theory suggests that in order to achieve the respect deserved from the international community, Africans would need to unite with one voice regardless of cultural differences. ${ }^{6}$

While this is a pan-Africanist ideology, he applied it to creating the national identity of Ghana by highlighting the commonalities of Ghanaian experience. Fearful of the fragility of cross-cultural bonds, Nkrumah's government sought to avoid conflict among the fifty ethnic tribes now enclosed in Ghana's borders. Nkrumah's pan-African rhetoric 
was 'rooted in the "age-old" quest for unity shared among Africans... African history that implied some sense of union in cast parts of the African continent.' ${ }^{\prime}$ The Ghanaian government has continued to facilitate unity through diversity as seen in the Government Cultural Commission's Cultural Policy which states:

Ghana has over fifty ethnic groups whose common values and institutions represent our collective national heritage. Each of these ethnic groups brought together by dint of history, has unique cultural features and traditions that give Identity, self-respect, and pride to the people. Since independence, the emerging civil society of Ghana has recognized the need to promote Unity within this cultural diversity and Ghana has since enjoyed relative unity, stability, and peace... to foster unity among the diverse ethnic groups of Ghana is indeed a daunting task. But the National Commission hopes to achieve this by promoting cultural interaction and inter-ethnic understanding through programmes that create enabling environment for national development.

The Ghanaian boundaries may have been created by its former colonial masters, but the Ghanaian identity was created by Ghanaians seeking to unify an ethnically diverse land by emphasizing their commonalities and celebrating their diversity.

THE OBRONI EXPERIENCE: INTERNATIONAL RESEARCH AND INTERNSHIP In 2010, I toured Cape Coast and Elmina Castles during the tourist aspect of a month-long medical outreach program with Rice University. I was first introduced to these structures through Saidiya Hartman's Lose Your Mother during an undergraduate course in American Slavery. But it was on my tour of these castles that I realized what I wanted to study. The interpretation of the buildings through tours and museums fascinated me. While giving out the typical information including dates and countries responsible for construction, these interpretations had an overwhelmingly African diasporic theme. The forts and castles of Ghana, listed as World Heritage sites in 1979, served as warehouses for European goods awaiting departure from the West African coast including gold, grains and black bodies. Built along 160 miles of coastline, over eighty forts and castles were constructed across three centuries by seven different European nations. Most fortifications exchanged hands as European and Ghanaian states battled one another 
for control of the Gold Coast shoreline, all fighting for dominion over trade. While over twenty of these fortifications have stood the test of time, the memory surrounding them has been transformed. I returned to Cape Coast, Ghana's fourth largest city, in 2011 for a semester abroad. This time, my express purpose was to investigate the museum interpretations of both Cape Coast and Elmina Castles. In the summer of 2014, I returned to Ghana to conduct graduate research on the history of the interpretations and preservation motives of the forts and castles that dot Ghana's tropical coastline.

While my thesis research required that I travel to the remains of the coastal structures, the University of South Carolina's Public History program required I gain real world experience through a summer internship. Because I had already spent several months based in Cape Coast, and because the majority of research holdings are located in Accra, I inquired after an internship at the National Museum of Ghana. The National Museum was strategically located next to the Public Records Office and housed within the same building as the Ghana Museum and Monuments Board, which is the entity in charge of the forts and castles.

I was assigned to one of the principle curators and worked in tandem with a group of students from the University of Cape Coast's Hospitality and Tourism department in addition to independently researching the forts and castles. My internship projects included assisting with writing and editing a grant proposal for the quincentennial anniversary of Fort Saint Anthony in Axim, practicing exhibition development, and conducting a museum analysis which will be discussed in the next section. The grant proposal was an intriguing experience because it was a general proposal being sent to several international agencies as well as the Ghanaian economic development grants; the grant sought to rehabilitate the building, revise the museum display to include local history, and build a restaurant to support the expected increase in tourism to the region. The grant was an especially interesting lens to view the importance of tourism to the country; according to the World Travel and Tourism Council's 2013 report, the total contribution of travel and tourism to Ghana's GDP was 7.2\% contributing to $2.3 \%$ of the countries employment. ${ }^{\circ}$ My internship work with exhibition development began with pictorial storyboard development, then shifted to presentation, and lastly with design and display mock-ups; I chose two different topics, one based on a research paper on Russo-American relations during the Civil War and the other on the public transportation system in Ghana, which I was becoming 
very familiar with thanks to my research travel and daily commute from the museum to my hostel. My first exhibit was a practice in converting historical document research into a visual format while the second sought to create a possible temporary exhibition aimed at tourists visiting the museum.

My internship projects were my first introduction to the practical challenges of running a museum in Ghana; financial restraints and access to materials would be reoccurring issues during my stay. While access to government money can be understood by most museum professionals, the National Museum's constant battle to acquire funds in order to create new exhibitions or purchase new artefacts would certainly explain issues that will be discussed within my museum analysis. Access to printing materials proved to be very challenging in my assignments as well as for the museum; while the museum had printers; they were for limited use and were typically out of ink. While there are hundreds of printing shops across Accra, the cost to print in colour, which would be required for including maps, diagrams or photographs within exhibitions, was extremely high due to the cost of importing inks and other printing materials into the country. Also due to the humidity, all museum panels required lamination, another expense that limited the museum's ability to create new exhibitions or update the permanent exhibition. While my internship projects highlighted the limitations of working in museum within Ghana, they also introduced me to the importance of tourism, which was an integral part of the grant proposal and one of my exhibitions. It was this interest in developing tourism that would result in my largest project, a museum analysis from the perspective of an obroni.

Strolling through the streets of my temporary home in the Darkuman neighborhood of Accra, small children ran out from alleyways screaming: 'Obroni, how are you? I am fine. Thank you, and you?', all the while smiling eagerly waiting for a response. While various definitions of obroni exist, it is most commonly used as a differentiation between white and black. It is a chant I heard throughout my travels along the coast, regardless of what local language was spoken. I usually joined in the chant by swaying my head back and forth in time; but instead of simply smiling and nodding as most foreigners do, I repeat the chant but in Twi, replacing obroni (white) with obibini (black):

'Obibini, etesen? Booko. Medase, na wo so eh?'. Most children look back stunned while nearby adults begin to laugh. Although I am an AfricanAmerican, because of my light skin and mixed racial identity, I was consistently called out to as obroni. Perhaps it is the nature of considering identity within academic research. But I found myself questioning my 
role as an obroni. Should I correct stranger's racial misidentification of me, or should I accept the definition of obroni as foreigner?

The identity of obroni continued into my internship when I was asked to conduct an analysis of the National Museum from the perspective of an obroni; my museum colleagues used the term obroni to differentiate between African and non-African, which is another common interpretation of the word. Driven by the desire to interpret the museum for an increasingly international audience in order to expand its touristic feature, the National Museum hoped that my analysis would offer a perspective of their narrative previously unattainable. This was the most interesting and influential task assigned while interning at the museum because it required me to critique Ghanaian museum practice juxtaposed to my American training. While my main critiques focused on the unnecessarily long and disjointed narrative, upon greater reflection I began to not only question how the museum's narrative had been crafted, but why obronis' perspectives mattered to the National Museum of Ghana.

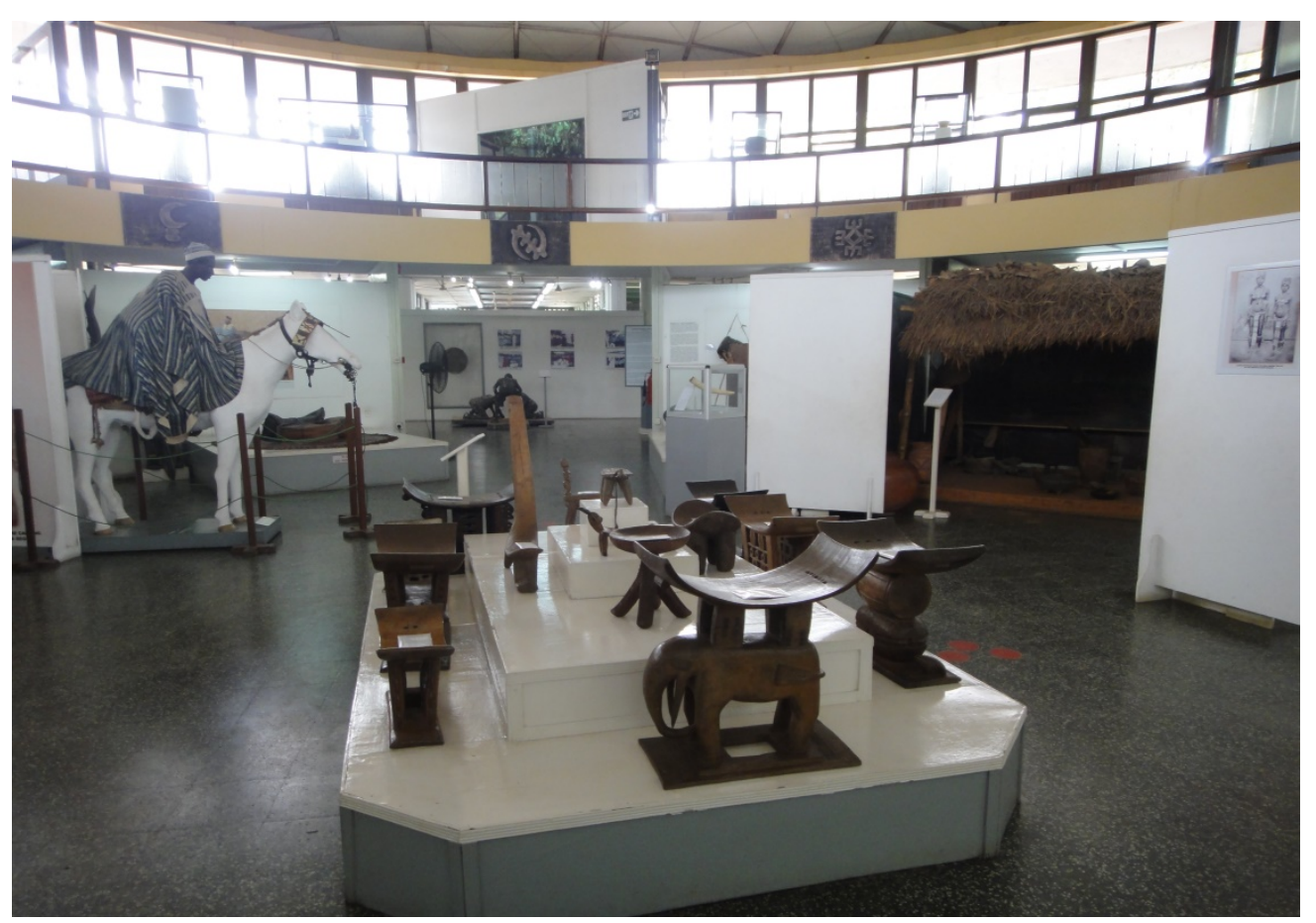

Fig 1: Interior view of the Main Hall which houses Cultural Bridges shows the variety of display types 
THE NATIONAL MUSEUM: INSTITUTIONAL HISTORY AND MUSEUM ANALYSIS

I was asked by the Public Relations and Communications officer to conduct a museum analysis of the National Museum from the perspective of an obroni visitor to the museum. I conducted the analysis critiquing the 'oddities' of the museum from the perspective of someone trained in and accustomed to Western museum practices. It was only after completing my thesis that I looked back upon my museum analysis and did a bit of self-reflection. My thesis, as a result of my summer research and an influential professor, became a sort of institutional history of the ownership of the preservation and interpretation of the slave forts and castles; it ultimately caused me to question my initial museum analysis because I had neglected the history of the museum and its collection. Instead of simply pointing out the oddities in Ghanaian museum practice, I began to understand and appreciate their origins. An institutional history is like the historiography of a museum; it examines the origins of the museum in order to understand its development over time. This can be done through an investigation of the history of the museum's collection, varying curatorial visions, or it's constantly changing mission. The National Museum states that its purpose is to display 'Ghana's past, her traditions' and culture. ${ }^{10}$ However, the most intriguing aspect of any national museum is the rhetoric surrounding the formation of a national identity.

The history of the National Museum of Ghana begins with the founding of Achimota College in the 1920s when the now independent nation was the British Colony of the Gold Coast. The governor of Gold Coast, Sir Gordon Guggisburg, thought that Africans were not the intellectual inferiors to Europeans and 'had the mental capacity for formal education.' "He founded Achimota College in 1924 hoping that it would "produce a type of student that was "Western" in his intellectual attitude towards life, with a respect for science and capacity for sympathetic thought and desirous of preserving and developing what was deserving of respect in 'tribal' life, custom, rule and law.' ${ }^{\prime 2}$ This purpose was later refined by Charles Thurston Shaw, the British professor of archaeology who was responsible for the creation of Achimota's Anthropology Museum. Shaw argued that the purpose of the museum, whose collection consisted primarily of West African archaeological objects, was 'to cultivate in the student a respect for the customs and traditions of his country [and] was to turn him ultimately

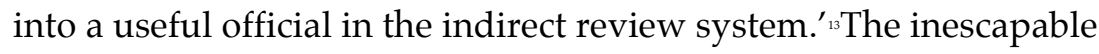
colonial purpose of Achimota's Anthropology Museum would affect its collections which consisted of British administrators, missionaries and 
amateur archaeologists' donations which included a variety of artefacts from across West Africa and the British Empire." The inclusion of the British Empire beyond the continent of West Africa could be ascribed to the collecting practices of those donating, but a reinterpretation of these objects could lead to an exhibition with the transnational theme of empire, which pushed the emergence of transnationalism within a British context in the late twentieth century. ${ }^{15}$

The British application of indirect rule was first perfected with the chiefdoms of Northern Nigeria and used throughout their holdings in West Africa and the majority of other African territories. Essentially, British political administrators and officers were advisors 'who only in extreme circumstances interfered with the chief and the native authority under' them. ${ }^{16}$ This system of rule was not to preserve local tradition, but was used to support 'local self-government through indigenous political institutions. ${ }^{\prime \prime}$ It was the fusion of the traditional institution and democratically elected councils that the British believed would alleviate the burden of ruling numerous colonial territories. They could only hope to continue control through the influence of the elected councils by educating local populations, through schools like Achimota College. Harmann Justus Braunholtz, the British Museum's ethnographer, was sent for two months in 1946 by the British government to survey Nigeria, the Gold Coast, Sierra Leone, and the Gambia in order to 'advise the governments... with regard to the preservation of West African antiquities.' 's Braunholtz emphasized the importance of material culture in establishing an African past for Africans 'from which will spring confidence in his future progress. ${ }^{\prime}{ }^{19}$ Following Braunholtz's recommendation, a National Museum would be constructed in Accra, while regionally focused museums would be later built to support the National Museum and allow for more thorough investigations of the various regions. Today there are two regional museums, Volta and Upper East, ran by the GMMB in addition to locally focused museums located within the slave castles in Cape Coast, Elmina and Axim. Other regions have cultural centers which act as regional museums but use cultural experiences like dance and music instead of artefacts to convey information.

The University College of the Gold Coast, now the University of Ghana, was created in 1940 and the Achimota collection of 10,000 objects and twenty-nine showcases was donated to the engineering department before being transferred to the archaeology department. ${ }^{20}$ The collection resided at the university until the completion of the museum which opened on the eve of Ghana's independence on 5 March 1957.21 The 
National Museum is an ethnographic, archaeological, and art museum that is essentially separated into five sections: the main exhibition 'Cultural Bridges in Ghana', 'Preserving Our Heritage - The Role of Youth', the second floor's archaeology exhibit, an exhibition on the Transatlantic slave trade, and a temporary exhibition hall. The museum's exhibitions are not well divided, and as a result of an undefined museum path, most visitors enter and exit the various exhibitions resulting in a confusion of narrative. Asking a tour guide the path she took in the museum proved museum's lack of direction; visitors are pin-balled from one side of the museum to the other in order for a cohesive narrative to be told, but are only led to do this by a guide. The various sections have extremely different goals and lack any sense of continuity other than the fact that they all deal with Ghanaian culture. This analysis focuses on each section individually, although most visitors and the museum, view them as one large exhibition.

\section{CULTURAL BRIDGES}

Cultural Bridges aims to show the difference and similarities within Ghana highlighting textiles, music, food pathways, metallurgy and puberty rights. The introductory panel is symbolic of the rampant textual issues throughout the museum. As a result of their length and inaccessibly academic language, panels meant to explain are often ignored. Visitors rarely read through the entire introductory panel resulting in a lack of context to view the differences and similarities the museum hopes to display. My final analysis included a word count of each panel, the Flesh-Kincaid Reading Ease, a highlight of the major ideas and a suggested revision. For instance, the introductory panel is 380 words rating at 32.9 reading scale which translates to a University education level; the inclusion of words such as idiosyncratic, paradigm, ethnic frontier and cultural transmission are understood by scholars within the humanities. But are not explained to a general museum audience. While standard practice allows for 250 words within a long text panel, this panel length of 380 words is usually glanced at by visitors.

While the story of unity through diversity is lost in the length and reading ease of the introductory text panel, differences are articulated through investigation of various types of weaving, royal stools and musical instruments. Within these examples fantastic parallels and differences are drawn to show the diversity within Ghana's borders while highlighting the common creativity and meticulous craftsmanship. The royal stools are an opportunity to discuss the traditional 
government's structure as well as Akan symbology that continues to flourish throughout Ghana and West Africa. The National Museum has an impressive collection ranging in origin, size, symbology and age; half of the collection is on display within cultural bridges while the other half is located in a room with musical instruments that seems to serve as an 'overflow' space.

Within the National Museum the Fante, Ashanti, Ga, Twi, Ewe and Anlos are discussed without introduction demonstrating the museum's focus on a narrative for its Ghanaian visitors. While the unity through diversity rhetoric can be found throughout the museum it is barely introduced, leaving an international audience questioning displays that seem to jump from ethnic group to ethnic group for some inexplicable reason. This is one example of how important knowing a museum's history and original intent because it demonstrates a very vital message of Ghanaian identity but without explanation visitors are left questioning the display narrative. Although it is a better-known African Independence story because of Nkrumah's Pan-African contribution, the majority of obronis visiting the museum are unaware of the intentions of displaying multiple tribes within one space. I suggested that a map which shows political boundaries overlaid on the regions where the different major tribes are found. Not only would this offer context for the variations within the ethnic tribal dress and weaponry, but would also afford the museum the opportunity to discuss the illogical political boundaries that cut tribes like the Ewe amongst three nations, Ghana, Togo and Benin.

The National Museum's displays illustrate the concept of 'unity in diversity' amongst Ghanaian identity by contrasting major ethnic groups' material culture. But it also takes into consideration the PanAfrican rhetoric through an examination of West African jewelry, masks, metallurgy and pottery. Certainly a result of the Achimota museum's initial collection practices, including jewellery and ritual dolls from the majority of West African nations. While I, as a museum professional, can ascertain that displaying objects with different national origins is meant to offer an opportunity for visitors to form their own opinions on the similarities and differences, the current curation of the displays greatly inhibits this process due to a lack of space and inconsistent display methods. I suggested a simple addition of a museum panels that ask questions; this leads visitors to compare the artefacts, instead of assuming that they will. I challenged my museum colleagues to reconsider what information the visitor should already know walking into the museum. By reviewing their text panels and asking what 
assumptions they were making of their visitors, they could certainly ascertain and fill-in the exhibition's narrative holes.

As stated before, not all museum oddities can be explained away by institutional histories; some oddities are created by cultural difference. It is important to immerse yourself in the culture of your host country. Instead of taking a taxi from my hostel in Darkuman to the National Museum downtown, I chose to ride the tro-tro-system which the majority of Ghanaians use to get around. Vans and buses that varied in capacity from fifteen to thirty passengers travel along predetermined routes at undetermined times. From accepting phone calls were more important than in-person conversations, to listening to loud ministers shouting the gospel on the bus, my rides on the tro-tro proved to serve as slices of the Ghanaian culture I would experience throughout my months there. A male obroni counterpart once experienced culture shock while riding on the bus with me; a woman began breastfeeding her child right next to him. While Western culture obviously shies from exposed breasts as seen in the 'Free the Nipple' movement and continuing digs against Instagram's sexist nude policies, Ghanaian culture has a very different stance. Within the section on puberty rights, which are the first several images to greet visitors entering the museum, there are several photographs of naked teenagers going through ritual ceremonies. While through the eyes of a Ghanaian this image is not startling, to an obroni a woman's exposed breast may be very shocking. I made a note in my report of this cultural difference, arguing that perhaps the best course of action was to move the pictures from the entrance, but keep them displayed elsewhere.

Before exiting Cultural Bridges, visitors learn about music. Any obroni realizes the importance of music to Ghanaian culture within minutes of arriving due to its constant presence in the street, markets, taxis and restaurants. However, the National Museum's interpretation focuses on why man makes music, instead of Ghanaian music. By discussing the power of music to man, the National Museum may connect to obronis. But it neglects to inform visitors of what Ghana's music is. While there are several types of drums, drumsticks and horns, there is no information available to the visitor. Labels could explain the origins and purpose of the drums, allowing visitors to see how they are used in different contexts as a way of understanding Ghanaian cultural practices. Instead of investigating the origins of Ghanaian music, the narrative focuses on the universality of music and deviates from the previous purpose of examining cultural bridges within Ghana and sometimes West Africa. I suggested a panel that examines the purpose of music as communication highlighting the talking drums still used within 
traditional ceremonies. It would also be helpful to hear the instruments through an audio or visual source, instead of allowing the visitor to imagine the sound.

\section{Preserving OUR Heritage: The Role of Youth}

Breaking from the 'unity in diversity' museum narrative, visitors move from music to dance which is an excellent transition. Preserving Our Heritage seeks to encourage youth to continue Ghanaian cultural practices emphasizing dancing, festivals, carving and agriculture. Created for the International Council of Museum's 2006 Museum Day Celebration, this exhibition forces the theme of 'Museum and Young People' onto cultural practices. While I appreciate the National Museum's attempt for cultural regeneration within Ghanaian youth, this exhibit is unwarrantedly separated from the main exhibition. The sections that focus on traditional dancing and festivals are interwoven given that many traditional dancing occurs at the various festivals.

Figures with the correct style of clothing illustrate the difference in not only dance moves, but costuming that some traditional dances demand. Again, I would suggest including an audio-visual component that could further highlight the importance of the actual dance, not just the costume. This exhibit then dramatically shifts focus to the art of Ghanaian wood carving from religious figures to eating utensils. Because of the brevity of this section, I suggested combining it with earlier sections of Cultural Bridges, for instance during the discussion of rural kitchens in which the carving and symbology of ceremonial spoons and bowls is discussed. Instead of focusing on the differences and similarities that combine to create Ghana's unique culture, this section of the museum breaks that narrative; but only for a moment. Following the sections in the back hall the visitors re-enter the primary hall where most visitors then finish the Cultural Bridges narrative, although the visitor is supposed to climb stairs to the second floor. As I stated in the introduction to the museum analysis, a fundamental flaw of the permanent exhibition is its lack of direction. I suggested a new organization to the exhibit that would only require reorganizing the sections so that a more cohesive narrative is told, one that essentially follows the tours path in a linear fashion. If the visitor continues the exhibition up the stairs, 'unity in diversity' is re-introduced through an examination of archaeological objects.

ARCHAEOLOGY

The archaeology exhibition is another example of the larger issue of 
organisation within the museum because it provides numerous examples of confusing displays but interesting artefacts. For instance, a wonderful display on ritual carvings within an imagined forest space allows for visitors to see the objects in their 'original' environment. However, there is not a text panel that explains why these objects would be located in a forest, or even what purpose they serve. Although the narrative could again be easily re-organized to show the importance of archaeology in understanding the past, it currently displays archaeological artefacts with little context other than labels which explain where digs occurred. I am by no means a trained archaeologist, but I can guarantee that the current display does not help the image of archaeology.

There is a wonderful miniature exhibition on the excavations done on some of the forts and castles in Ghana that provides an excellent example of how we learn about the past from archaeology. However, it is dispersed within an area that talks about digs throughout the country. While possible to integrate new narratives into existing ones, it is obvious that the miniature exhibition was not a part of the larger archaeological exhibition and is an addition. Casts of Nigerian, Egyptian, and Greco-Roman archaeological artifacts are displayed at the end of the exhibition without any context. Again visitors are left to their own interpretation, instead of being guided by the museum to compare the artistic features Nigerian face mask with the Komaland terracotta figures visitors are left to assume they see these objects side-by-side because they are found within the same region. The National Museum claims to be an ethnology, archaeology and art museum, but the archaeology portion is lacking in any real narrative. It should be re-organized with a set goal of informing the visitor about archaeology instead of just showcasing archaeological objects without interpretation. The museum has a large archaeological collection, most of it is in the museum vault, with objects and replicas from across the continent and world which could be used to reiterate the Pan-African themes found in Cultural Bridges, but I argued that these artefacts and information about their digs should be integrated into Cultural Bridges instead of being separated. The museum should use all of its objects in tandem to argue its narrative.

\section{TRANSATLANTIC SLAVE TRADE}

The visitor should then descend the stair and enter the last section of the museum. Ending the National Museum with difficult knowledge like the transatlantic slave trade is not typical of national museum rhetoric. While it is an important piece of Ghanaian history, and should be 
included in the museums narrative, it is the only purely historical theme of the museum. It is clear that this section was carefully curated as a result of the amount of space devoted to the topic and because of this there is a very distinct change in the style of which the topic is covered. Instead of introductory texts that cover basic concepts, this section focuses on both typical and unique themes within the transatlantic slave trade. One unique theme that most visitors have not heard of is resistance to slave raiding; the panels associated with the topic examine the various methods in which Ghanaians used their landscape as a means to protect themselves. Another interesting topic discussed is weaponry; it could use further interpretation that would educate visitors on European antagonism of tribes for the purpose of procuring more slaves, but now offers examples of desired European weaponry juxtaposed to traditional Ghanaian armament.

My own biases and interests resulted in a deeper analysis of the last portion of the museums which focuses on Ghana's role in the transatlantic slave trade. Through the use of their collection, the National Museums offers visitors both traditional narratives of Ghanaian involvement in the slave trade as well as lesser-known strategies of resistance. The treatment of the interpretation of the slave forts and castles within the museum is modelled upon the narrative told at these historic sites. Listed as World Heritage properties, these buildings have most recently been interpreted through international collaboration with UNESCO, the Smithsonian, and the Ghana Museums and Monuments Board. As a result of the international collaboration, and subsequent push for development via tourism, a metanarrative that heavily focuses on the transatlantic slave trade with an emphasis on African Diaspora experience is used within the National Museum and on tours at some forts and castles.

Again, it is important to examine the origins of this interpretation beginning with the initial preservation of the buildings by the British Relics and Monuments Commission of the Gold Coast in the 1920s. The original catalyst for preservation emphasized the unique European fortification architecture in tandem with discussions of the trade basis of the forts and castles. Following the independence of Ghana, the Ghana Museum and Monuments Board, born from the Relics and Monuments Commission, shifted interpretive focus to the equitable relationship between Africans and Europeans best described as an immediate postcolonial reaction. The current interpretation mostly neglects the architectural emphasis and counters the post-colonial economic parity narratives surrounding the slave forts and castles as a result of 
international collaborations which pushed the interpretation to consider the role of the structures for humanity. By involving international institutions in the process of interpreting sites, the narrative has been expanded to view the sites as international sites which link Blacks around the world to Africa. While this complicates the narrative in sometimes problematic ways, by approaching these buildings with international implications in mind a different narrative is produced allowing for the multilayered history of the forts and castles to be recognised.

An element in this final section of the museum that is inappropriate and should be eliminated is the 'Door of No Return'. This is the exit that slaves would emerge from the damp, dark dungeon spaces which they had been confined into the sunlight, only to be chained and stored in darkness again within the holds of a slave ship. The term 'Door of No Return' was invented to create a connection between the past and present. 'Thru the Door of No Return - The Return' was a program developed for the PANAFEST, a festival that brings Africans and African Diasporans into conversations surrounding the impact of the trans-Atlantic slave trade, by African Diasporans to emphasize 'the sacredness of the site'..$^{2}$ PANAFEST, which is thrown bi-annually to 'reconnect Africans in the diaspora with their African roots', is celebrated in conjunction with Ghana's annual Emancipation Day celebration. ${ }^{23}$ Reed points out 'that Rawlings selected August 1 over Juneteenth for recognition in Ghana could be used as evidence that he was interested in reaching out to a wide array of diasporans', not just African Americans. ${ }^{24}$ Depending upon the accessibility of the exit, visitors are invited to walk through the door. On the outside of the fort or castle the guide provides a brief description of the trans-Atlantic passage and plantation slave system. Guests are then invited through the 'Door of Return', allowing African Diasporans to complete the spiritual journey of their ancestors on their heritage tour.

The 'invented tradition' of the 'Door of No Return' demonstrate that through the creation of new ceremonies groups can create 'continuity with the old' in order to preserve a historic past..5 First ascribed in 1998, Cape Coast Castle's 'Door of Return' was created following the ceremony of returning two former slaves' remain to Africa; following the coffin procession into the courtyard, 'libation was poured' and the entry was renamed. ${ }^{26}$ The historical narrative of return is created by appropriating African concepts of death and African American ideals of homeland and is placed upon the exits from the forts and castles, turning the buildings into the physical manifestation of the physical and spiritual rift from Africa forced upon African Diasporans predecessors. The 
National Museum's 'Door of No Return', comprised of a black curtain, references the forts and castles that are briefly discussed within the museum, but the crude recreation of the ominous symbol loses any power outside of the actual space. It is arguably insulting to the actual Doors of No Return.

The last section of the museum discusses the forts and castles involved with the slave trade. It provides an opportunity to discuss World Heritage status and what it means for those buildings to be inscribed on the World Heritage List. However, there are over twenty forts and castles inscribed, yet only the three largest are discussed. This space would provide an excellent opportunity to discuss those forts and castles that are not tourist destinations or easily accessible showcasing the magnitude, complexity and diversity within the trade.

\section{CONCLUSION}

While now operating as a post-colonial institution, the museum was founded near the end of the British Gold Coast Colony and was consequently affected. The Western museum structure is an obvious lasting legacy of colonialism which ignores previous transmitters of history and memory, yet the National Museum has been able to use this setting to create a nationalizing rhetoric which aims to demonstrate the differences amongst the ethnic groups of Ghana. While this message shows tourists the variety of culture within Ghana - through an examination of various cultural elements like religion, dance, or attire it reminds Ghanaians, and visitors familiar with Nkrumah identity formation rhetoric, of unity through diversity. My obroni analysis emphasized the importance of self-reflection when examining museum narratives as well as challenged the current method of creating individual exhibitions and then fitting them into the museum's larger narrative.

Ultimately, it is essential to understand the history and development within international discourses of public history in order to truly collaborate. My experience working internationally has made me realize the limitations other countries face in regards to access to materials. But more importantly it required me to approach issues with cultural differences in mind. My international experience as a research and as an intern has helped develop my museum philosophy by requiring an understanding of the importance of the historical origins of institution as well as the limitations of museum funded by financially constrained governments. It also taught me to hold off judgement on oddities and search for possible reasons for their existence. Each contributor must 
understand and appreciate the differences within public historiographies in order to truly understand where approaches converge and diverge in order for productive collaborations to flourish. Ultimately, my international experiences provided me with another lens to view the power museums have through their artefacts and careful curation in creating a national identity. 'Unity in Diversity' has proven to be a successful rhetoric and program allowing a variety of ethnicities and religions to co-exist with little conflict. The National Museum has its faults, primarily a lack of organization and excessive and inaccessible labels. But its overall argument clearly reflects the national identity created during the country's initial conception.

\section{ENDNOTES}

Robin D. G. Kelley, “"But a Local Phase of a World Problem”: Black History's Global Vision', Journal of American History, vol 86, 1999, pp1045.

Kelley, "'But a Local Phase of a World Problem"', pp1045-77; Ian Tyrell, 'What is transnational history?', paper given at the Ecole des Hautes Etudes en Sciences Sociale, 2007. Available: https: / / iantyrrell.wordpress.com/what-is-transnational-history/ (accessed August 2015). ibid, Tyrrell.

- World Fact Book - www.cia.gov/library/publications/the-world-factbook/geos/gh.html.

5 Benjamin W. Kankpeyeng and Christopher R. DeCorse, 'Ghana's Vanishing Past: Development, Antiquities, and the Destruction of the Archaeological Record', African Archaeological Review, vol 1, no 2, 2004, p94.

- Harcourt Fuller, Building the Ghanaian Nation-State: Kwame Nkrumah's Symbolic Nationalism, Palgrave Macmillan, London, 2014, p221.

The Pan-African rhetoric used by Nkrumah created both the Ghanaian and African Diasporan identity, but for now this section will only examine the Ghanaian; D. Zizwe Poe, Kwame Nkrumah's Contribution to Pan-Africanism: An Afrocentric Analysis, Routledge, London, 2003, p60.

sames Anquandah, 2006, 'Ghanaian Culture, National Identity and Development' (Online). Available: http:// www.ghanaculture.gov.gh/modules/mod_pdf.php?sectionid=666 (accessed 27 February 2015).

http: / / www.wttc.org/-

/ media/files / reports / economic\%20impact\%20research/country\%20reports/ghana2014.pdf

${ }^{10}$ http: / / www.ghanamuseums.org/national-museum.php

"Arianna Fogelman, 2008, 'Tradition, Urbanity and "Colonial Legacy" at the Ghana National Museum' (Online), p8. Available:

http://museumstudies.columbian.gwu.edu/sites/museumstudies.columbian.gwu.edu/files /downloads/TraditionUrbanityandColonialLegacyattheGhanaNationalMuseum.pdf (accessed 6 May 2015); Francis Agbodeka, 1977, Achimota in the National Setting: A Unique Educational Experiement in West Africa, Afram Publications, Accra, p32.

"Fogelman, p8; Agbodeka, p32.

${ }^{13}$ Agbodeka, p33.

${ }^{\text {" }}$ Mark Crinson, 2001, 'Nation-Building, collecting and the politics of display: The National Museum, Ghana', Journal of the History of Collections, vol 13, no 2, pp231-250.

${ }^{15}$ Ann Curthoys and Marilyn Lake, Connected Worlds: History in Transnational Perspective, Australian National University E Press, Canberra, 2005, p8.

${ }^{16}$ Michael Crowder, 'Indirect Rule - French and British Style', Journal of the International African Institute, vol 34, no 3, 1964, p198.

${ }^{17}$ ibid.

Fsogelman, p6.

${ }^{19}$ ibid.

${ }^{20}$ ibid, p8.

${ }^{21}$ http:// / www.ghanamuseums.org/national-museum.php.

Ann Reed, Pilgrimage Tourism of Diaspora Africans to Ghana, Rutledge, London, 2014, p143. 
${ }^{2}$ Bayo Hosley, Routes of Remembrance: Refashioning the Slave Trade in Ghana, University of Chicago Press, Chicago, 2008, p58.

" Reed, Pilgrimage Tourism, p1110.

$\therefore$ Eric Hobsbawm and Terence Ranger (eds), The Invention of Tradition, Cambridge University, Cambridge, 1983, p2; Klaus Benesch and Genevieve Fabre, African Diasporas in the New and Old Worlds: Consciousness and Imagination, Rodopi, Leiden, 2004, p165.

${ }^{x}$ Reed, Pilgrimage Tourism, p1120. 